\title{
The association of water supply, sanitation and hygiene interventions and childhood malnutrition in Kersa and Omo Nada districts of Jimma Zone, Ethiopia: A case-control study
}

\author{
Negasa Eshete Soboksa ${ }^{1 *}$, Sirak Robele Gari ${ }^{1}$, Abebe Beyene Hailu ${ }^{2}$ and Bezatu Mengistie Alemu ${ }^{3}$ \\ ${ }^{1}$ Ethiopian Institute of Water Resources, Addis Ababa University, Addis Ababa, Ethiopia \\ ${ }^{2}$ Department of Environmental Health sciences, Jimma University, Jimma, Ethiopia \\ ${ }^{3}$ Colleges of Health and Medical Sciences, Haramaya University, Harar, Ethiopia \\ * Correspondence: yeroosaa@gmail.com
}

\begin{abstract}
Background: Malnutrition is the widely known nutritional disorder and one of the leading causes of morbidity and mortality among children in developing countries like Ethiopia. About $50 \%$ of under-nutrition around the world is associated with infections caused by unsafe water, inadequate sanitation or insufficient hygiene. However, there are limited available data which associate water supply, sanitation and hygiene practices and childhood malnutrition in Ethiopia particularly in the study area. Therefore, the objective of this study was designed to examine the association of water supply, sanitation and hygiene interventions and childhood malnutrition.
\end{abstract}

Methods: Case-control study design was conducted from December 2018 to January 2019 Kersa and Omo Nada districts of Jimma Zone, Southwest Ethiopia. Randomly 126 cases and 252 controls were selected from the malnourished children and normal children, respectively. A pretested, structured, interviewer-administered questionnaire was used. Bivariate and multivariable logistic regression analyses were used to identify the study variables associated with childhood malnutrition and to adjust for confounders. The crude and adjusted odds ratios with $95 \%$ confidence interval was calculated to assess the level of significance and reported for each confounding variable.

Results: The results of this study showed that children living with mothers/caregivers lack of formal education were found to have 57\% times less likely developed malnourished, compared to those living with mother/caregiver who attended secondary and above (AOR $=0.57 ; 95 \%$ CI: 0.26-1.24). The odds of having malnutrition were increased among children who were breastfed after one hour of birth $(\mathrm{AOR}=2.60$; 95\% CI: 1.02-6.65) and children who had diarrhea (AOR=9.50; 95\% CI: 5.1917.36).Collecting water from a distance of less than/equal to one kilometer ( $\mathrm{AOR}=2.52$; $95 \% \mathrm{CI}$ : 0.56- 
11.39), defecating in open pit(AOR=1.33; 95\% CI: 0.62-2.83), under-five children open field defecation practices $(\mathrm{AOR}=1.17 ; 95 \% \mathrm{CI}: 0.42-3.23)$ and lack of hand washing at critical times $(\mathrm{AOR}=2.38 ; 95 \%$ CI: 1.07-5.29) were positively associated with childhood malnutrition.

Conclusion: We conclude that improvement in the initiation of breastfeeding within one hour, diarrhea prevention, use of improved latrine and hand washing at critical times is needed to improve the nutritional status of children.

Keywords: water supply; sanitation; hygiene; intervention; childhood malnutrition

\section{Background}

Malnutrition is the widely known nutritional disorder and one of the leading causes of morbidity and mortality among children in developing countries like Ethiopia [1-3]. Lack of access to highly nutritious foods is a common cause of malnutrition. Malnutrition results from inadequate food intake and infectious diseases like frequent or persistent diarrhea, pneumonia, measles and malaria [4]. In addition to food insecurity, inappropriate care practices and poor access to health care, an unhealthy environment, including inadequate access to water, sanitation, and hygiene are basic determinants of malnutrition [5,6]. The World Health Organization (WHO) estimates that 50\% of under-nutrition around the world is associated with infections caused by unsafe water, inadequate sanitation or insufficient hygiene [7].

Poor WASH interventions create the perfect conditions for the development of different infectious diseases that are linked to malnutrition [8,9]. These poor interventions can affect a child's nutritional status at least in three direct pathways: via diarrheal diseases, intestinal parasite infections, and environmental enteropathy. It may indirectly impact the nutritional status of children by necessitating walking long distances in search of water and sanitation facilities and diverting a mother's time away from childcare [10]. Children themselves may become affected by environmental contamination as they start crawling, walking, exploring and putting objects in their mouths, which increases the risk of ingesting fecal bacteria from both humans and animal sources. This leads to repeated bouts of diarrhea and intestinal worms, which in turn deteriorates the nutritional status of children [11,12]. The WASH Benefits and SHINE trials reports showed detection of enteropathogens among children in the WASH groups of the trials was typically at ten times higher prevalence compared with high-income countries[13]. But, 
recent study findings reported that there were little or no impact of selected WASH interventions on reducing childhood diarrhea and stunting [14-17].

Previous studies showed that socioeconomic factor, poor nutrition, and poor mothers' knowledge and feeding practices led to an increase in the prevalence of malnutrition $[2,18,19]$. A metaanalysis of data from cluster-randomized controlled trials concluded that WASH intervention shad a benefit on the improvement of the nutritional status in under five years of age children [20]. Specifically, studies report from different parts of Ethiopia showed that the presence of childhood diarrhea, safe disposal of child's feces and use of soap for hand washing were risk factors for childhood malnutrition [21-23].

There are limited available studies which link water supply, sanitation and hygiene interventions and childhood malnutrition in Ethiopia. Thus, this study was designed to examine the association of household water supply, sanitation and hygiene interventions and childhood malnutrition Kersa and Omo Nada districts of Jimma Zone, Southwest Ethiopia. The results of this study could help policymakers, program planners, donors and concerned bodies to prevent malnutrition. It may also serve as a baseline for further studies for organizations working on this area.

The conceptual frame work of this study that adapted from previously done study [20] was presented below in Figure 1. In the proposed conceptual framework, we tried to show the link between childhood malnutrition and water supply, sanitation and hygiene intervention.

\section{Methods and materials}

\section{Study design and setting}

Case-Control study design was conducted in two purposely selected districts (Kersa and Omo Nada) of Jimma Zone, Oromia Regional State, Ethiopia from December 2018 to January 2019. The Zonal capital, Jimma town, is located $357 \mathrm{~km}$ away from Addis Ababa in southwest Ethiopia. The Zone extends between 7013' - 8056' North latitudes and 35049 -38038' East longitudes and also the altitude range from 1740 to 2660 above sea level. Agriculture is the major source of economy and it includes mainly growing coffee and cattle rearing (Figure 2). 


\section{Source population}

All children from 6 to 59 months, living Kersa and Omo Nada districts with Z-score of weightfor-height (wasting) $<-2$ (SD), weight-for-age (underweight) $<-2 \mathrm{SD}$, height-for-age (stunting) $<$ -2 SD, mid upper arm circumference (MUAC) less than $11.5 \mathrm{~cm}$ or have edema were sourced population of cases; whereas all children from 6 to 59 months with Z-score of weight-for-height2 to $+2 \mathrm{SD}$, weight-for-age -2 to $+2 \mathrm{SD}$, height-for-age -2 to $+2 \mathrm{SD}$, or MUAC above $12 \mathrm{~cm}$ or have no edema based on growth reference of $\mathrm{WHO} 24]$ were sourced population of controls.

\section{Inclusion and exclusion criteria}

All children aged 6-59 months that have malnutrition, and their mothers' resided as district member for a year were included in cases. Whereas all children 6-59 months of age and have no malnutrition and their mothers resided as a district member for a year were included for control. Children whose mothers are seriously ill and could not communicate to give information were excluded from the study.

\section{Sample size determination and sampling procedure}

The sample size was determined using a formula for calculating double population proportion by assuming estimates of proportion of normal children $\left(\mathrm{P}_{2}\right)$ as $43.8 \%$ (taking water sources as a major factor (14)), $\alpha$ at 95\% confidence level (1.96), odd ratio 1.89 (from literature, children living in households that had been using unprotected water sources were 1.89 times more likely to be acutely malnourished than those who had been using protected water sources (15)), power $=80 \%(0.84)$, the ratio of cases to controls is $1: 2$. The study considered a $10 \%$ non-response rate and the required sample size was computed mathematically as equation 1 follow:

$$
\begin{gathered}
\boldsymbol{n}=\left(\frac{r+\mathbf{1}}{r}\right) \frac{(\overline{\boldsymbol{p}})(\mathbf{1}-\overline{\boldsymbol{p}})\left(\boldsymbol{Z}_{\beta}+\mathbf{Z}_{\alpha / 2}\right)^{2}}{\left(\mathbf{p}_{1}-\mathbf{p}_{2}\right)^{2}} \\
\quad \text { Where } p_{1}=\frac{O R p_{2}}{p_{2}(O R-1)+1} \\
\quad \bar{p}=\frac{\mathrm{p}_{1}+p_{2}}{2}
\end{gathered}
$$


This implies that 117 cases and 234 controls were required. After adding $10 \%$ for non-response rate, the final samples were 128 for cases and 256 controls.

Five health centers, which have children's malnutrition treatment center, were selected purposely from the two selected districts. Then, three kebeles (the smallest administrative structure) (high, medium and low kebeles based on malnutrition case report) from each were selected and the census was conducted to identify the number of under-five children in the kebeles and their nutritional status. Then the cases were randomly selected from the malnourished children and controls were randomly selected from normal children.

\section{Anthropometric measurement}

Body weight, length/height, mid-upper arm circumference, presence of edema of the children were measured in a similar fashion with previously conducted research and based on the WHO references $[2,24,25]$. Weight and height of the children were measured by salter scale and measuring board instrument, respectively. The body weight of all children was measured without shoes to the nearest $0.1 \mathrm{~g}$ whereas height/length of children was measured using a measuring board to the nearest $0.1 \mathrm{~cm}$. Each measurement was done twice, and the mean of the two readings was recorded. Then, using the weight/height reference table, we interpret the anthropometric measurements through the weight-for-height, weight-for-age, height-for-age percentage or standard deviation score (Z-score). Thumb pressure was applied on the upper side of both feet for three seconds to diagnose the presence of edema. The presence was diagnosed if a bilateral depression (pitting) remained after the press release. Mid-upper arm circumference was measured in centimeters using MUAC tape on the left arm and was recorded to the nearest $0.1 \mathrm{~cm}$. Based on the Z-score, edema and MUAC value recorded and the nutritional status of children was identified using cutoff points recommended by the World Health Organization [24]. Confirmed malnourished children were linked to the health center after consultation of the data collector.

\section{Data collection instruments}

Data were collected from mothers or caretakers of the children using pretested, standardized interviewer-administered questionnaire (regarding socio-demographic and economic, dietary, medical and health care). The questionnaire adapted from the WHO/UNICEF Joint Monitoring 
Program for Water Supply, Sanitation, and Hygiene 2017 core questions on water, sanitation and hygiene for household surveys [26] and the similar instrument used by previous studies[2,18,19]. Some questions were revised to suit the context of the study by the principal investigator.

It consists of maternal and child characteristics, sources of water for domestic uses and distance from home, their water storage practices, and water treatment techniques known and/or used in their households and hygienic and sanitation practices by asking questions like the practice of hand washing with soap/any detergent at critical times (after defecation, before handling food/water, before feeding a child, after cleaning child stool), covering drinking water storage and clean water containers regularly before filling, habits of touch/ dipping fingers in water during collection, place of defecation, latrine utilization by all family members, disposal system of children feces and domestic waste. The wealth index was developed from assets and other housing characteristics. Hand washing at critical times was assessed by asking whether they washed their hands after defecation, before handling food/water, before feeding a child or after cleaning child stool. If they responded yes for all of these hand washing time, we said always hand washing at critical times or if at least one missed we said sometimes they washed their hands at critical times. Mothers/caregivers were asked the age of their children or assess on immunization card if present. If they didn't know the age or didn't have immunization card, data collectors were asked whether the child was born before or after known holidays. They were also asked about any occurrence of diarrhea and vaccine status based on the age of the child to identify the past two weeks of diarrhea and vaccination of children.

\section{Data collection and quality}

The data were collected by health professionals through face to face interview of mothers. The questionnaire used for this data collection was prepared originally in English and then translated into the local language (Afan Oromo) and back retranslated into English to check its consistency by public health and linguistics professionals. Then, necessary correction and modification of the instrument were made.

Mother's interview and anthropometric measurement were done by data collectors following two days of intensive training which included orientation, demonstration, and field procedures. Pretest of the instrument and the procedure was conducted on 5\% of mothers or caregivers of the children in the selected households before actual data collection. Anthropometric measurements 
were done by using calibrated and pretested scales. The overall day to day data collection process, completeness of the collected questionnaires and any other amendments were followed and given by supervisors and principal investigator.

\section{Data analyses}

Data were entered, cleaned and checked for correctness using EpiData version 4.2 and then after exportation, all statistical analyses were carried out using the using SPSS version 24. Data were described by frequency, percentage and mean (for continuous data) to compare the cases and controls. The wealth status of the household was computed from the households' asset ownership and housing characteristics using principal component analysis[27]. It was categorized in poor, middle and rich. A binary logistic regression model was used to assess whether water supply, sanitation, and hygiene practice are associated with childhood malnutrition. Bivariate analysis was used to identify the study variables associated with childhood malnutrition and to adjust for confounders multivariable logistic regression analyses were used. All variables that had a pvalue of 0.25 or less in bivariate analysis were included in the multivariable analysis. The crude and adjusted odds ratios (OR) with 95\% confidence intervals for variables were computed and reported. For both analyses, a variable that had a p-value $<0.05$ was considered as statistically significant.

\section{Results}

\section{Study population characteristics}

A total of 378 children, 126 cases and 252 controls, were included in this study with a response rate of 98.44\%. The mean ages of these children were 31.2 ( $\mathrm{SD} \pm 8.5$ ) months in cases and 30.1( \pm 12.2 ) months in controls. Regarding the sex of children, $61.9 \%$ of cases and $57.5 \%$ of controls were male. Seventy three percent of cases and $23 \%$ of control children had diarrhea at least once in the past two weeks during the visit. The mean ages of mothers of cases were $28.6( \pm 3.1)$ years and controls were 28.1( \pm 2.9$)$ years. Forty four percent of cases and 38.9\% controls of the respondents were mothers' no/lack of formal education. In this study, $30.16 \%$ of cases and $35.32 \%$ of controls belong to the poor wealth index, whereas $31.75 \%$ of cases and $34.13 \%$ of controls were from good wealthy status, relatively (Table 1).

The main sources of drinking water of the households of $96.8 \%$ of cases and $92.5 \%$ of controls were from protected sources. With regard to the mean daily water consumption of study participants, $16.2( \pm 27.8)$ liters per capita per person for cases and $14.9( \pm 11.2)$ liters per capita per person for controls. The mean 
time to fetch water was $45.2( \pm 16.8)$ minutes for cases and $39.7( \pm 19.5)$ minutes for controls. In addition, the approximate distances of drinking water sources from the home of both populations were almost less than one kilometer. Sixty three percent of cases and $75.8 \%$ of controls reported that the amount of collecting water as insufficient. Seventy six percent of cases and $84.8 \%$ of controls further explained that the main reason for the inability to access sufficient quantities of water when needed was the unavailability of water in the source. In the home of $91.3 \%$ cases and $93.7 \%$ controls, there were no water treatment practices at the point of use (Table 2).

Eighty one percent of households of cases and $75.4 \%$ of households of controls used pit latrines with the slab/superstructure for defecation. Almost all these latrines were not shared with other households in both cases and controls. Nineteen percent of cases and $9 \%$ of controls do not wash their hands at critical times (Table 3).

\section{Risk factors of childhood malnutrition}

Bivariate analysis of socio-demographic and childhood malnutrition was computed at a $95 \%$ confidence interval. In the analysis, variables like the initiation of breastfeeding, length of child breastfeed (months) and the presence of diarrhea in the past two weeks were significantly associated with childhood malnutrition. There was a positive association between childhood malnutrition and lack of formal education of mothers, large family size and under-five in the households. The odds of having childhood malnutrition were reduced by $8 \%$ among children live with mother's index as economically poor compared those mothers grouped as the wealthiest ( $\mathrm{COR}=0.92: 95 \% \mathrm{CI}$ : 0.54-1.57). Initiation of breastfeeding after 1 hour of birth $(\mathrm{COR}=3.73$ : 95\% CI: 2.29 -6.08) and presence of diarrhea (COR=9.05: 95\% CI: 5.54-14.78) more likely increases the risk of childhood malnutrition (Table 1).

Table 1: Bivariate analysis of socio-demographic characteristics and childhood malnutrition among study participants Kersa and Omo Nada districts of Jimma Zone, Ethiopia

\begin{tabular}{|l|l|l|l|l|}
\hline \multirow{2}{*}{ Variables } & Cases & Controls & Crude \\
\cline { 2 - 5 } & No (\%) & No (\%) & OR (95\% CI) \\
\hline \multirow{3}{*}{ Age of mother } & $19-25$ & $31(24.6)$ & $70(27.8)$ & $0.69(0.34-1.39)$ \\
\cline { 2 - 5 } & $26-31$ & $75(59.5)$ & $151(59.9)$ & $0.77(0.41-1.44)$ \\
\cline { 2 - 5 } & $32-39$ & $20(15.9)$ & $31(12.3)$ & 1 \\
\hline \multirow{2}{*}{ Family size } & $\leq 5$ & $43(34.1)$ & $88(34.9)$ & 1 \\
\cline { 2 - 5 } & $>5$ & $83(65.9)$ & $164(65.1)$ & $1.04(0.66-1.62)$ \\
\hline \multirow{2}{*}{$\begin{array}{l}\text { Number of under-five } \\
\text { children in the households }\end{array}$} & 1 & $77(61.1)$ & $169(67.1)$ & 1 \\
\cline { 2 - 5 } & 2 & $49(38.9)$ & $83(32.9)$ & $1.30(0.83-2.02)$ \\
\hline
\end{tabular}




\begin{tabular}{|l|l|l|l|l|}
\hline $\begin{array}{l}\text { Educational status of the } \\
\text { mother/caregiver of the } \\
\text { child }\end{array}$ & $\begin{array}{l}\text { No/lack of formal } \\
\text { education }\end{array}$ & $56(44.4)$ & $98(38.9)$ & $1.25(0.82-1.94)$ \\
\cline { 2 - 5 } & Literate & $70(55.6)$ & $154(61.1)$ & 1 \\
\hline \multirow{2}{*}{ Sex of the child } & Female & $48(38.1)$ & $107(42.5)$ & $0.83(0.54-1.29)$ \\
\cline { 2 - 5 } & Male & $78(61.9)$ & $145(57.5)$ & 1 \\
\hline \multirow{2}{*}{$\begin{array}{l}\text { Initiation of breastfeeding } \\
\text { Child breastfeed (Months) }\end{array}$} & After 1 hour of birth & $53(42.1)$ & $41(16.3)$ & $3.73(2.29-6.08)^{*}$ \\
\cline { 2 - 5 } & Within 1 hour of birth & $73(57.9)$ & $211(83.7)$ & 1 \\
\cline { 2 - 5 } & up to 24 & $92(73.0)$ & $131(52.0)$ & 1 \\
\cline { 2 - 5 } & still now & $22(17.5)$ & $95(37.7)$ & $0.33(0.19-0.56)^{*}$ \\
\hline \multirow{2}{*}{$\begin{array}{l}\text { Age of first introduce } \\
\text { liquids or foods to the } \\
\text { baby(Months) }\end{array}$} & Below 6 & $12(9.5)$ & $26(10.3)$ & $0.66(0.62-1.37)$ \\
\hline \multirow{2}{*}{$\begin{array}{l}\text { Had diarrhea at least once } \\
\text { in the past two week(s) }\end{array}$} & 6 & $9(7.1)$ & $5(2.0)$ & $3.80(0.98-10.55)$ \\
\hline & yes & $117(92.9)$ & $247(98.0)$ & 1 \\
\hline \multirow{2}{*}{\begin{tabular}{l} 
Wealth index \\
\cline { 2 - 5 }
\end{tabular}} & No & $92(73.0)$ & $58(23.0)$ & $9.05(5.54-14.78)^{*}$ \\
\cline { 2 - 5 } & Poor & $34(27.0)$ & $194(77.0)$ & 1 \\
\hline & Medium & $38(30.16)$ & $89(35.32)$ & $0.92(0.54-1.57)$ \\
\hline \multirow{2}{*}{$\begin{array}{l}\text { Wealthiest } \\
*\end{array}$} & $48(38.10)$ & $77(30.56)$ & $1.34(0.80-2.25)$ \\
\hline
\end{tabular}

*Significant at $\mathrm{p}<0.05$

Bivariate analysis of water supply and childhood malnutrition was also computed. Accordingly, distances of water sources, time to fetch water, the sufficiency of water they get and cleaning of drinking water storage container had a statistically significant association with childhood malnutrition in the binary analysis The odds of exposure to malnutrition among children live in households who collected drinking water from a distance of less than/equal to one kilometer was significantly higher than children live in households who collected water from a distance of greater than one kilometer $(\mathrm{COR}=5.53$ : 95\% CI: $1.03-12.13)$. The likelihood of malnutrition was also increased if the time taken to water sources (time take to go there, get water, and come back) was greater than 30 minutes $(\mathrm{COR}=1.62$ : 95\% CI: 1.05-2.50).But, the odds of having malnourished children were decreased by $46 \%$ when the water they get was not sufficient (COR=0.54: 95\% CI: 0.54-0.85) (Table 2).

Table 2: Bivariate analysis of drinking water supply related characteristics and childhood malnutrition among study participants Kersa and Omo Nada districts of Jimma Zone, Ethiopia

\begin{tabular}{|l|l|l|l|l|}
\hline \multicolumn{2}{|l|}{ Variables } & Cases & Controls & Crude \\
\cline { 3 - 4 } & No $(\%)$ & No $(\%)$ & OR (95\% CI) \\
\hline The main source of drinking-water & Protected sources & $122(96.8)$ & $223(92.5)$ & 1 \\
\hline
\end{tabular}




\begin{tabular}{|c|c|c|c|c|}
\hline & Unprotected sources & $4(3.2)$ & $19(7.5)$ & $0.40(0.13-1.21)$ \\
\hline \multirow{2}{*}{$\begin{array}{l}\text { The main source of water used by } \\
\text { households for cooking and washing }\end{array}$} & Protected sources & $115(91.3)$ & $214(84.9)$ & 1 \\
\hline & Unprotected sources & $11(8.7)$ & $38(15.1)$ & $0.54(0.67-1.09)$ \\
\hline \multirow{2}{*}{$\begin{array}{l}\text { The distance of drinking water sources } \\
(\mathrm{Km})\end{array}$} & less than/equal to 1 & $123(97.6)$ & $232(92.1)$ & $5.53(1.03-12.13)^{*}$ \\
\hline & greater than 1 & $3(2.4)$ & 20(7.9) & 1 \\
\hline \multirow{2}{*}{$\begin{array}{l}\text { Time to take to go there, get water, and } \\
\text { come back (minutes) }\end{array}$} & $\leq 30$ & $50(39.7)$ & $130(51.6)$ & 1 \\
\hline & $>30$ & $76(60.3)$ & $122(48.4)$ & $1.62(1.05-2.50)^{*}$ \\
\hline \multirow[t]{2}{*}{ Amount of water get sufficient } & Sufficient & $47(37.3)$ & $61(24.2)$ & 1 \\
\hline & Not sufficient & $79(62.7)$ & $191(75.8)$ & $0.54(0.54-0.85)^{*}$ \\
\hline \multirow{3}{*}{$\begin{array}{l}\text { The main reason for unable to access } \\
\text { sufficient quantities of water when } \\
\text { needed }\end{array}$} & $\begin{array}{l}\text { water not available } \\
\text { from the source }\end{array}$ & $60(75.9)$ & $162(84.8)$ & 1 \\
\hline & water too expensive & $5(6.3)$ & $4(2.1)$ & $3.37(0.89-12.99)$ \\
\hline & source not accessible & $14(17.7)$ & $25(13.1)$ & $1.51(0.74-3.10)$ \\
\hline \multirow{2}{*}{$\begin{array}{l}\text { Kind of drinking water storage } \\
\text { containers }\end{array}$} & Narrow-mouthed & $122(96.8)$ & $249(98.8$ & $0.37(0.08-1.67)$ \\
\hline & $\begin{array}{l}\text { Both narrow and wide } \\
\text { mouthed }\end{array}$ & $4(3.2)$ & $3(1.2)$ & 1 \\
\hline \multirow{3}{*}{$\begin{array}{l}\text { Cleaning of drinking water storage } \\
\text { container }\end{array}$} & Daily & $54(42.9)$ & $73(29.0)$ & 1 \\
\hline & $\begin{array}{l}\text { Several times per } \\
\text { week }\end{array}$ & $17(13.5)$ & $17(6.7)$ & $1.35(0.63-2.89)$ \\
\hline & Once a week & $55(43.7)$ & $162(64.3)$ & $0.46(0.29-0.73)^{*}$ \\
\hline $\begin{array}{l}\text { Method of water taken from the } \\
\text { drinking water containers }\end{array}$ & Pouring & $126(100)$ & $252(100)$ & - \\
\hline \multirow{2}{*}{$\begin{array}{l}\text { Household level drinking water } \\
\text { treatment }\end{array}$} & Treat & $11(8.7)$ & $16(6.3)$ & 1 \\
\hline & Not treat & $115(91.3)$ & $236(93.7)$ & $0.71(0.32-1.58)$ \\
\hline
\end{tabular}

*Significant at $\mathrm{p}<0.05$

According to the bivariate analysis of sanitation and hygiene characteristics and childhood malnutrition, place of defecation of the family members, the place where under-five children usually go to defecate, child feces disposal methods, household domestic waste disposal site and hand washing at the critical times were statistically significantly associated with childhood malnutrition. In this analysis, children live in households those practiced open defecation were 2.28 times more likely exposed to malnutrition compared to children live with those used latrine $(\mathrm{COR}=2.28$ : $95 \% \mathrm{CI}$ : 
1.04-4.99). Deposing domestic waste on open area was increasing the odds of childhood malnutrition by $20 \%$, compared to households used the pit for disposing of (COR=1.20: $95 \% \mathrm{CI}$ : 0.63-2.29) (Table 3).

Table 3: Bivariate analysis of sanitation and hygiene practices and childhood malnutrition among study participants Kersa and Omo Nada districts of Jimma Zone, Ethiopia

\begin{tabular}{|c|c|c|c|c|}
\hline \multirow{2}{*}{\multicolumn{2}{|c|}{ Variables }} & Cases & Controls & \multirow{2}{*}{$\begin{array}{l}\text { Crude OR } \\
(95 \% \mathrm{CI})\end{array}$} \\
\hline & & \multirow{2}{*}{$\begin{array}{l}\text { No }(\%) \\
102(81.0) \\
\end{array}$} & \multirow{2}{*}{$\begin{array}{l}\text { No }(\%) \\
190(75.4) \\
\end{array}$} & \\
\hline \multirow[t]{2}{*}{ Place of defecation } & Pit latrine with slab & & & 1 \\
\hline & $\begin{array}{l}\text { Pit latrine without slab/open } \\
\text { pit }\end{array}$ & $24(19.0)$ & $62(24.6)$ & $2.43(1.55-3.81)^{*}$ \\
\hline \multirow{2}{*}{$\begin{array}{l}\text { Share the facility with others } \\
\text { household }\end{array}$} & Yes & $1(0.8)$ & $9(3.6)$ & $0.21(0.03-1.72)$ \\
\hline & No & $125(99.2)$ & 243(96.4) & 1 \\
\hline \multirow{2}{*}{$\begin{array}{l}\text { Do all household members use } \\
\text { the latrine? }\end{array}$} & Yes always & $122(96.8)$ & $247(98.0)$ & 1 \\
\hline & Yes sometime & $4(3.2)$ & $5(2.0)$ & $1.62(0.43-6.14)$ \\
\hline Latrine facility location & In own yard / plot & $126(100)$ & $252(100)$ & - \\
\hline \multirow{2}{*}{$\begin{array}{l}\text { Access and use of latrine at all } \\
\text { times of the day and night by } \\
\text { household members }\end{array}$} & Yes & $107(84.9)$ & $213(84.5)$ & $1.03(0.57-1.87)$ \\
\hline & No & $19(15.1)$ & $39(15.5)$ & 1 \\
\hline \multirow{2}{*}{$\begin{array}{l}\text { The main reason why household } \\
\text { members were unable to access } \\
\text { and use the latrine at all times of } \\
\text { the day and night }\end{array}$} & Unable to use the toilet & $5(26.3)$ & $6(15.4)$ & $0.51(0.13-1.95)$ \\
\hline & others & $14(73.7)$ & $33(84.6)$ & 1 \\
\hline \multirow{3}{*}{$\begin{array}{l}\text { Place where under } 5 \text { children } \\
\text { usually go to defecate }\end{array}$} & household/public latrine & $13(10.3)$ & $51(20.2)$ & 1 \\
\hline & Open defecation & $62(49.2)$ & $117(46.4)$ & $2.28(1.04-4.99)^{*}$ \\
\hline & others & $51(40.5)$ & $84(33.3)$ & $2.54(1.13-5.69)^{*}$ \\
\hline \multirow{2}{*}{$\begin{array}{l}\text { If there are children under } 5 \text { who } \\
\text { didn't use the latrine what is } \\
\text { done with their feces? }\end{array}$} & $\begin{array}{l}\text { Collected and disposed of in } \\
\text { the latrine }\end{array}$ & $125(99.2)$ & $228(90.5)$ & 1 \\
\hline & $\begin{array}{l}\text { Collected and disposed of } \\
\text { elsewhere }\end{array}$ & $1(0.8)$ & $24(9.5)$ & $0.08(0.01-0.57)^{*}$ \\
\hline \multirow{3}{*}{$\begin{array}{l}\text { Households domestic waste } \\
\text { disposal place }\end{array}$} & Household waste pit & $45(35.7)$ & $60(23.8)$ & 1 \\
\hline & Open area & $27(21.4)$ & $30(11.9)$ & $1.20(0.63-2.29)$ \\
\hline & Burned & $54(42.9)$ & $162(64.3)$ & $0.44(0.27-0.73)^{*}$ \\
\hline \multirow{4}{*}{$\begin{array}{l}\text { Latrine most often used have } \\
\text { hand washing facilities with } \\
\text { soap }\end{array}$} & Yes, with soap and water & $4(3.2)$ & $6(2.4)$ & 1 \\
\hline & Sometimes & $44(34.9)$ & $57(22.6)$ & $1.16(0.71-4.35)$ \\
\hline & Take own soap and water & - & $14(5.6)$ & - \\
\hline & No & $78(61.9)$ & $175(69.4)$ & $0.67(0.18-2.44)$ \\
\hline \multirow{2}{*}{$\begin{array}{l}\text { Hand washing at the critical } \\
\text { time }\end{array}$} & Yes, Always & $102(81.0)$ & $229(90.9)$ & 1 \\
\hline & Some times & $24(19.0)$ & $23(9.1)$ & $2.34(1.26-4.34)^{*}$ \\
\hline
\end{tabular}


*Significant at $\mathrm{p}<0.05$

The multivariable analysis results of childhood malnutrition with water supply, sanitation, and hygiene intervention are presented in Table 4. Initiation of breastfeeding, the presence of diarrhea, wealth index, place of defecation, under 5 children feces disposal sitesand hand washing at critical times were statistically significantly associated with childhood malnutrition. After adjustment, no significant associations were found between the distance of drinking water sources, time taken to get water, amount of water they get, cleaning of drinking water storage container, under 5 children usually go to defecation place and domestic waste disposal sites with childhood malnutrition.

Children living with mother/caregiver lack of formal education were found to have $98 \%$ times less likely developed malnourished, compared to those living with secondary and above mother/caregiver $(\mathrm{AOR}=0.98 ; 95 \% \mathrm{CI}: 0.53-1.82)$. The odds of having malnutrition among children who were breastfed after one hour of birth were increased compared to children who were breastfed within one after birth $(\mathrm{AOR}=2.59 ; 95 \% \mathrm{CI}$ : 1.08-6.18). Similarly, the level of malnutrition was higher in children who had diarrhea at least once in the past two weeks compared with those who did not have diarrhea (AOR $=9.34 ; 95 \%$ CI: 5.19-16.81).

Families, who collected drinking water from a distance of less than/equal to one kilometer, were 4.55 times more likely to have malnourished children compared to those who collected from greater than one kilometer $(\mathrm{AOR}=4.55 ; 95 \% \mathrm{CI}$ : 0.92-22.56). The odds of having malnutrition were decreased $78 \%$ times among children living in families who used narrow-mouthed drinking water storage compared to those living with used both(COR=0.22; 95\% CI: 0.02-2.13).

Under-five children who defected in the open field were 1.29times more likely malnourished than children living in the household who defecated in latrines ( $\mathrm{AOR}=1.29 ; 95 \% \mathrm{CI}$ : 0.47-3.57). Households who dispose of their domestic waste in open places were found to have more malnourished children compared to those who dispose of wastes in the pits(AOR=1.05; 95\% CI: 0.29-3.83). The odds of having childhood malnutrition were 2.52 times higher among children living with mothers who wash their hands sometimes at critical times (AOR=2.52; 95\% CI: 1.10 5.75) compared to those who wash always (Table 4). 


\section{Discussion}

Many factors affecting the nutritional status of children in a developing country like Ethiopia. In the present study, our objective was designed to examine the association of the household water supply, sanitation and hygiene interventions and childhood malnutrition among children 6-59 months in Kersa and Omo Nada districts of Jimma Zone, Ethiopia. In this study, we found evidence that child breastfeed for less than 24 months and dispose of under-five children feces elsewhere were significantly reduced the odds of having childhood malnutrition. Whereas initiation of breastfeeding after one hour of birth, having diarrhea at least once in the past two weeks, poorest wealth status, living with families who defecting in a pit latrine without slab/open pit and lack of hand washing at critical time were significantly increased the likelihood of childhood malnutrition.

In our study finding, educational level of mothers/caregivers and childhood malnutrition were negatively associated in multivariable model. This study finding was inconsistent with studies done in Malaysia, India, and Ethiopia, which stated that mothers/caregivers education has definite and significant effect on nutritional status of children $[19,28,29]$. This might be due to the fact that even though they have a high educational level, they wouldn't have better practical skills to keep sanitation and hygiene of their children or have no better information to provide an adequate diet to keep the nutritional status of their children.

Consistent with other previously conducted studies in a different world [19,30], our study showed a strong association of childhood malnutrition and poorest wealth status. In poor households, mothers might have inadequate access to socio-economic resources to meet the nutritional needs of their children.

In this study having diarrhea among children was shown to be a significant predictor for childhood malnutrition. Our finding revealed that the presence of the preceding two weeks of childhood diarrhea and malnutrition was positively associated. The finding of this study was consistent with the previous finding that showed the presence of childhood diarrhea increased the risk of malnutrition [21,22]. But, inconsistent with the study report from Northwest Ethiopia [29]. This inconsistent might be due to the socio-economic difference of the study participants.

Collecting drinking water from improved sources was related to the reduction of water contamination by infectious agents that may be competing for the absorption of nutrients when 
ingested. However, we found that collecting water from protected (improved) sources was increased the odds of having childhood malnutrition. Studies reported in Ethiopia and Indonesia were contradicting our study finding $[31,32]$. The difference could be related re-contamination of water during transportation or lack household water treatment and safe storage practices [33].

In our study, collecting water from a distance of less than/equal to one kilometer water sources was found to be a strong predictor of childhood malnutrition. This implies that the nearest sources they used might be unprotected water sources that expose them to fecal bacteria and intestinal worms, which in turn deteriorates the nutritional status of children by malabsorption. This study was supported by other studies done in rural Ethiopia and Kenya $[31,34]$

This analysis shows there was the inverse association between household access to a toilet facility and childhood malnutrition. Our study finding incline to confirm the findings of other studies carried out in Ethiopia and other parts of the world [19,31,35]. Improper disposal of waste causes environmental contamination that can affect a child's nutritional status via environmental enteric dysfunction (enteropathy). This might happen when children are repeatedly exposed to pathogenic bacteria that prevent absorption of nutrients by damaging the intestinal mucosa [10]. Our study also supports this evidence in such a way that improper disposal of household domestic waste was the risk factor for childhood malnutrition. Our study finding was agreed with pooled evidence of a systematic review done on environmental risk factors associated with child stunting by Vilcins D, and others [36].

A proper hand washing with soap at critical times is an effective means of reducing pathogen transmission. The present study also found that always hand washing at critical times was negatively associated with childhood malnutrition. These findings were in line with studies conducted in Bangladesh and Armenia that revealed significant association of hand washing at critical times and childhood malnutrition [16,37]. Another cluster randomized controlled trial study done in Pakistan proved that hand washing promotion could improve the nutritional status of the children [38].

The limitation of this study was data related to nutrition and health status of mothers, the food security of households and type of dietary children consumed were not included in this study. 


\section{Conclusions}

The finding of this study confirmed that child breastfeed for less than 24 months and disposal of under-five children feces elsewhere were significantly reduced the odds of having malnutrition. Whereas initiation of breastfeeding after one hour of birth, having diarrhea at least once in the past two weeks, poorest wealth status, living with families who defecting in pit latrine without slab/open pit and lack of hand washing at critical time were significantly increased the likelihood of childhood malnutrition. This study finding suggested that promoting in the initiation of breastfeeding within one hour, preventing diarrhea, use of improved latrine and hand washing at critical times are needed to improve the nutritional status of children. WASH programmers and other NGOs working on child health should also be given emphasis to integrate nutrition with sanitation and hygiene program for awareness creation and community behavior change.

\section{Abbreviations}

AOR: Adjusted Odd Ratio; AOR: Adjusted Odd Ratio; CI: Confidence Interval; cm: centimeter; Km: Kilometer; MDG: Millennium Development Goal; MUAC: Mid-Upper Arm Circumference; SD: standard deviations; UNICEF: United Nations Children's Fund; WASH: water supply, sanitation and hygiene; WHO: World Health Organization

\section{Declarations}

Ethical approval and consent to participate: The study was reviewed and ethical clearance was secured from Addis Ababa University, Ethiopian Institute of Water Resources. Because of the high proportion of illiteracy to read consent form, an informed verbal consent was obtained from mothers/caregivers after explaining the purpose of the study. Mothers/caregivers were assured of confidentiality with regard to all information acquired. Children, who were found with childhood malnutrition during visits and those didn't start treatment, were linked to the health center after consultation.

Consent for publication: Not applicable

Availability of data and material: Contact the corresponding author for data and materials

Competing interests: The authors declare that they have no competing interests 
Funding: This work was supported by Addis Ababa University, Ethiopian Institute of Water Resources. The funders had no role in study design, data collection and analysis, decision to publish, or preparation of the manuscript.

Author's contributions: NES participated in the design of the study, conducted the statistical analysis, interpretation of data and drafted and revised the manuscript. ABH, BMA and SRG participated in the design of the study and critical review of the manuscript. All authors read and approved the final manuscript.

Acknowledgment: We would like to thank Kersa and Omo Nada districts for supporting us and unreserved cooperation during data collection. We acknowledge Mr. Elias Legessa for his suggestion and comments on the manuscript. Special thanks are also extended to the mothers/caregivers of the studied children for their commitment to providing information.

\section{References}

1. Müller O, Krawinkel M. Malnutrition and health in developing countries. CMAJ. 2005. p. 279-86.

2. Musa TH, Musa HH, Ali EA, Musa NE. Prevalence of malnutrition among children under five years old in Khartoum State, Sudan. Polish Ann Med. Polish Pediatric Society.; 2014;21:1-7.

3. Daboné C, Delisle HF, Receveur O. Poor nutritional status of schoolchildren in urban and peri-urban areas of Ouagadougou (Burkina Faso). Nutr J. BioMed Central; 2011;10:34.

4. World Health Organization. Malnutrition [Internet]. World Health Organization; 2011 [cited 2019 May 29]. Available from: https://www.who.int/maternal_child_adolescent/topics/child/malnutrition/en/

5. Dodos J, Mattern B, Lapegue J, Altmann M, Aissa MA. Relationship between water, sanitation, hygiene, and nutrition: What do Link NCA nutrition causal analyses say? Waterlines. 2017;36:284-304.

6. World Health Organization. Improving nutrition outcomes with better water, sanitation and hygiene:practical solutions for policies and programme. Geneva, Switzerland; 2015.

7. Prüss-Üstün A, Bos R, Gore F BJS. Safer water, better health: costs, benefits and sustainability of interventions to protect and promote health. World Heal. Organ. Geneva; 2008.

8. UNICEF. The role of water, sanitation \& hygiene in the fight against child undernutrition [Internet]. 2015. Available from: http://www.susana.org/_resources/documents/default/3-2385-7- 
1450185216.pdf

9. Ziegelbauer K, Speich B, Mäusezahl D, Bos R, Keiser J, Utzinger J. Effect of sanitation on soil-transmitted helminth infection: Systematic review and meta-analysis. PLoS Med. 2012. p. $1-17$.

10. Fenn B, Bulti AT, Nduna T, Duffield A, Watson F. An evaluation of an operations research project to reduce childhood stunting in a food-insecure area in Ethiopia. Public Health Nutr. 2012;15:1746-54.

11. Rah JH, Cronin AA, Badgaiyan B, Aguayo VM, Coates S, Ahmed S. Household sanitation and personal hygiene practices are associated with child stunting in rural India: A cross-sectional analysis of surveys. BMJ Open. 2015;5.

12. Humphrey JH. Child undernutrition, tropical enteropathy, toilets, and handwashing. Lancet. 2009;374:1032-5.

13. Pickering AJ, Null C, Winch PJ, Mangwadu G, Arnold BF, Prendergast AJ, et al. The WASH Benefits and SHINE trials: interpretation of WASH intervention effects on linear growth and diarrhoea. Lancet Glob Heal. 2019;7:e1139-46.

14. Null C, Stewart CP, Pickering AJ, Dentz HN, Arnold BF, Arnold CD, et al. Effects of water quality, sanitation, handwashing, and nutritional interventions on diarrhoea and child growth in rural Kenya: a cluster-randomised controlled trial. Lancet Glob Heal. 2018;6:e316-29.

15. Pickering AJ, Njenga SM, Steinbaum L, Swarthout J, Lin A, Arnold BF, et al. Effects of single and integrated water, sanitation, handwashing, and nutrition interventions on child soiltransmitted helminth and giardia infections: A cluster-randomized controlled trial in rural Kenya. PLoS Med. 2019;16:1-21.

16. Luby SP, Rahman M, Arnold BF, Unicomb L, Ashraf S, Winch PJ, et al. Effects of water quality, sanitation, handwashing, and nutritional interventions on diarrhoea and child growth in rural Bangladesh: a cluster randomised controlled trial. Lancet Glob Heal. 2018;6:e302-15.

17. Humphrey JH, Mbuya MNN, Ntozini R, Moulton LH, Stoltzfus RJ, Tavengwa N V., et al. Independent and combined effects of improved water, sanitation, and hygiene, and improved complementary feeding, on child stunting and anaemia in rural Zimbabwe: a cluster-randomised trial. Lancet Glob Heal. 2019;7:e132-47.

18. Amsalu S, Tigabu Z. Risk factors for severe acute malnutrition in children under the age of five : A case-control study. EthiopJHealth Dev. 2008;22:21-5. 
19. Wong HJ, Moy FM, Nair S. Risk factors of malnutrition among preschool children in Terengganu, Malaysia: a case control study. BMC Public Health. 2014;14:1-10.

20. Dangour AD, Watson L, Cumming O, Boisson S, Velleman Y, Cavill S, et al. Interventions to improve water quality and supply, sanitation and hygiene practices, and their effects on the nutritional status of children. Cochrane Database Syst Rev. 2011;

21. Fekadu Y, Mesfin A, Haile D, Stoecker BJ. Factors associated with nutritional status of infants and young children in Somali Region, Ethiopia: a cross- sectional study. BMC Public Health. BMC Public Health; 2015;18:1-9.

22. Amare D, Negesse A, Tsegaye B, Assefa B, Ayenie B. Prevalence of Undernutrition and Its Associated Factors among Children below Five Years of Age in Bure Town, West Gojjam Zone , Amhara National Regional State , Northwest Ethiopia. Adv Public Heal. 2016;18:1-8.

23. Darsene H, Geleto A, Gebeyehu A, Meseret S. Magnitude and predictors of undernutrition among children aged six to fifty nine months in Ethiopia: A cross sectional study. Arch Public Heal. Archives of Public Health; 2017;75:1-11.

24. World Health Organization. WHO Child Growth Standards. World Heal Organ [Internet]. 2006;80:1-312. Available from: https://www.who.int/childgrowth/standards/en/

25. Bantamen G, Belaynew W, Dube J. Assessment of Factors Associated with Malnutrition among Under Five Years Age Children at Machakel Woreda, Northwest Ethiopia: A Case Control Study Journal of Nutrition \& Food Sciences. 2014;4:1-7.

26. WHO/UNICEF. Core questions on drinking water and sanitation for household surveys. 2006.

27. Fry K., Firestone R. CNM. Measuring Equity with Nationally Representative Wealth Quintiles. Popul. Serv. Int. Washington DC; 2014.

28. Ansuya, Nayak BS, Unnikrishnan B, George A, Shashidhara NY, Mundkur SC, et al. Risk factors for malnutrition among preschool children in rural Karnataka: A case-control study. BMC Public Health. 2018;18:1-8.

29. Tilayie Feto Gelano, Nigusie Birhan MM. Prevalence of undernutrition and its associated factors among under- five children in gondar city, northwest ethiopia 2014 . J Harmon Res Med Heal Sci. 2015;2:163-74.

30. Ahsan KZ, Arifeen S El, Al-Mamun MA, Khan SH, Chakraborty N. Effects of individual, household and community characteristics on child nutritional status in the slums of urban 
Bangladesh. Arch Public Heal. Archives of Public Health; 2017;75:1-13.

31. van Cooten MH, Bilal SM, Gebremedhin S, Spigt M. The association between acute malnutrition and water, sanitation, and hygiene among children aged 6-59 months in rural Ethiopia. Matern Child Nutr. 2019;15:1-8.

32. Torlesse H, Cronin AA, Sebayang SK, Nandy R. Determinants of stunting in Indonesian children: Evidence from a cross-sectional survey indicate a prominent role for the water, sanitation and hygiene sector in stunting reduction. BMC Public Health. 2016;16:1-11.

33. Clasen TF, Cairncross S. Editorial: Household water management - Refining the dominant paradigm. Trop Med Int Heal. 2004;9:187-91.

34. Nygren BL, Reilly CEO, Rajasingham A, Omore R, Ombok M, Awuor AO, et al. The Relationship between Distance to Water Source and Moderate-to-Severe Diarrhea in the Global Enterics Multi-Center Study in Kenya , 2008 - 2011. Am J Trop Med Hyg. 2016;94:1143-9.

35. Masibo PK, Makoka D. Trends and determinants of undernutrition among young Kenyan children : Kenya Demographic and Health Survey; 1993 , 1998 , 2003 and 2008 - 2009. Public Heal Nutr. 2012;15:1715-27.

36. Vilcins D, Sly PD, Jagals P. Environmental Risk Factors Associated with Child Stunting: A Systematic Review of the Literature. Ann Glob Heal. 2018;84:551.

37. Demirchyan A, Petrosyan V. Hand hygiene predicts stunting among rural children in Armenia. Eur J Public Health. 2019;27:502-3.

38. Bowen Anna, Mubina Agboatwalla, Stephen Luby, Timothy Tobery TA and RMH. Association Between Intensive Handwashing Promotion and Child Development in Karachi, Pakistan. Arch Pediatr Adolesc Med. 2012;166:1037-44.

Figure 1: Conceptual frame work of this study that shows the association of WASH interventions and childhood malnutrition (bold overlapped arrow)

Figure 2: Map of the two selected study area from Jimma Zone, Ethiopia 
Table 4: Multivariable analysis of drinking water supply sanitation and hygiene intervention and childhood malnutrition among study participants Kersa and Omo Nada districts of Jimma Zone, Ethiopia

\begin{tabular}{|c|c|c|c|c|c|}
\hline \multicolumn{2}{|l|}{ Variables } & \multirow{2}{*}{$\begin{array}{l}\text { Case } \\
\text { No }(\%) \\
77(61.1)\end{array}$} & \multirow{2}{*}{$\begin{array}{l}\text { Control } \\
\text { No }(\%) \\
169(67.1)\end{array}$} & \multirow{2}{*}{$\begin{array}{l}\text { Crude } \\
\text { OR }(95 \% \mathrm{CI}) \\
1\end{array}$} & \multirow{2}{*}{$\begin{array}{l}\text { Adjusted } \\
\text { OR }(95 \% \text { CI }) \\
1\end{array}$} \\
\hline Number of under-five children & 1 & & & & \\
\hline & 2 & 49(38.9) & $83(32.9)$ & $1.30(0.83-2.02)$ & $1.13(0.62-2.06)$ \\
\hline \multirow[t]{2}{*}{$\begin{array}{l}\text { Educational status of the } \\
\text { mother/caregiver of the child }\end{array}$} & $\begin{array}{l}\text { No/lack of formal } \\
\text { education }\end{array}$ & $56(44.4)$ & $98(38.9)$ & $1.25(0.82-1.94)$ & $0.98(0.53-1.82)$ \\
\hline & Literate & $70(55.6)$ & $154(61.1)$ & 1 & 1 \\
\hline \multirow[t]{2}{*}{ Initiation of breast feeding } & After 1 hour of birth & $53(42.1)$ & $41(16.3)$ & $3.73(2.29-6.08) *$ & $2.59(1.08-6.18)^{*}$ \\
\hline & Within 1 hour of birth & 73(57.9) & $211(83.7)$ & 1 & 1 \\
\hline \multirow[t]{3}{*}{ Child breastfeed (Months) } & up to 24 & $92(73.0)$ & $131(52.0)$ & 1 & 1 \\
\hline & still now & $22(17.5)$ & $95(37.7)$ & $0.33(0.19-0.56)^{*}$ & $0.35(0.18-0.71)^{*}$ \\
\hline & Others $(<24)$ & $12(9.5)$ & $26(10.3)$ & $0.66(0.62-1.37)$ & $0.52(0.221-1.31)$ \\
\hline \multirow{2}{*}{$\begin{array}{l}\text { Had diarrhea at least once in the } \\
\text { past two week(s) }\end{array}$} & yes & $92(73.0)$ & $58(23.0)$ & $9.05(5.54-14.78)^{*}$ & 9.34(5.19-16.81)* \\
\hline & No & $34(27.0)$ & 194(77.0) & 1 & 1 \\
\hline \multirow[t]{3}{*}{ Wealth index } & Poor & $38(30.16)$ & $89(35.32)$ & $0.92(0.54-1.57)$ & $2.57(1.09-6.07)^{*}$ \\
\hline & Medium & $48(38.10)$ & $77(30.56)$ & $1.34(0.80-2.25)$ & $1.67(0.76-3.68)$ \\
\hline & Wealthiest & $40(31.75)$ & $86(34.13)$ & 1 & 1 \\
\hline \multirow{2}{*}{$\begin{array}{l}\text { The main source of drinking- } \\
\text { water }\end{array}$} & Protected sources & $122(96.8)$ & $223(92.5)$ & 1 & 1 \\
\hline & Unprotected sources & $4(3.2)$ & $19(7.5)$ & $0.40(0.13-1.21)$ & $0.35(0.05-2.32)$ \\
\hline \multirow{2}{*}{$\begin{array}{l}\text { The main source of water used } \\
\text { by households for cooking and } \\
\text { washing }\end{array}$} & Protected sources & $115(91.3)$ & $214(84.9)$ & 1 & 1 \\
\hline & Unprotected sources & $11(8.7)$ & $38(15.1)$ & $0.54(0.67-1.09)$ & $0.60(0.18-2.08)$ \\
\hline \multirow{2}{*}{$\begin{array}{l}\text { The distance of drinking water } \\
\text { sources }(\mathrm{Km})\end{array}$} & less than/equal to1 & 123(97.6) & 232(92.1) & $5.53(1.03-12.13)^{*}$ & 4.55(0.92-22.56) \\
\hline & greater than 1 & $3(2.4)$ & 20(7.9) & 1 & 1 \\
\hline \multirow{2}{*}{$\begin{array}{l}\text { Time to take to go there, get } \\
\text { water, and come back (minutes) }\end{array}$} & $\leq 30$ & $50(39.7)$ & $130(51.6)$ & 1 & 1 \\
\hline & $>30$ & $76(60.3)$ & $122(48.4)$ & $1.62(1.05-2.50)^{*}$ & $0.86(0.42-1.76)$ \\
\hline \multirow[t]{2}{*}{ Amount of water get sufficient } & Sufficient & $47(37.3)$ & $61(24.2)$ & 1 & 1 \\
\hline & Not sufficient & $79(62.7)$ & 191(75.8) & $0.54(0.54-0.85)^{*}$ & $0.43(0.09-2.00)$ \\
\hline \multirow{2}{*}{$\begin{array}{l}\text { Kind of drinking water storage } \\
\text { containers }\end{array}$} & Narrow-mouthed & $122(96.8)$ & $249(98.8$ & $0.37(0.08-1.67)$ & $0.22(0.02-2.13)$ \\
\hline & $\begin{array}{l}\text { Both narrow and wide } \\
\text { mouthed }\end{array}$ & $4(3.2)$ & $3(1.2)$ & 1 & 1 \\
\hline
\end{tabular}




\begin{tabular}{|l|l|l|l|l|l|}
\hline \multirow{2}{*}{$\begin{array}{l}\text { Cleaning of drinking water } \\
\text { storage container }\end{array}$} & Daily & $54(42.9)$ & $73(29.0)$ & 1 & 1 \\
\cline { 2 - 6 } & Several times per week & $17(13.5)$ & $17(6.7)$ & $1.35(0.63-2.89)$ & $1.97(0.49-7.00)$ \\
\cline { 2 - 6 } & Once a week & $55(43.7)$ & $162(64.3)$ & $0.46(0.29-0.73)^{*}$ & $1.23(0.35-4.31)$ \\
\hline \multirow{2}{*}{ Place of defecation } & Pit latrine with slab & $69(54.8)$ & $188(74.6)$ & 1 & 1 \\
\cline { 2 - 6 } & $\begin{array}{l}\text { Pit latrine without } \\
\text { slab/open pit }\end{array}$ & $57(45.2)$ & $64(25.4)$ & $2.43(1.55-3.81)^{*}$ & $2.49(1.17-5.30)^{*}$ \\
\hline $\begin{array}{l}\text { Place where under 5 children } \\
\text { usually go to defecate }\end{array}$ & Use latrine & $13(10.3)$ & $51(20.2)$ & 1 & 1 \\
\cline { 2 - 6 } & Open defecation & $62(49.2)$ & $117(46.4)$ & $2.28(1.04-4.99)^{*}$ & $1.29(0.47-3.57)$ \\
\cline { 2 - 6 } & Other & $51(40.5)$ & $84(33.3)$ & $2.54(1.13-5.69)^{*}$ & $0.73(0.16-3.34)$ \\
\hline \multirow{2}{*}{$\begin{array}{l}\text { If there are children under 5 who } \\
\text { didn't use the latrine what is }\end{array}$} & $\begin{array}{l}\text { Collected and disposed } \\
\text { of in the latrine }\end{array}$ & $125(99.2)$ & $228(90.5)$ & 1 & 1 \\
\cline { 2 - 6 } & $\begin{array}{l}\text { Collected and disposed } \\
\text { of elsewhere }\end{array}$ & $1(0.8)$ & $24(9.5)$ & $0.08(0.01-0.57)^{*}$ & $0.08(0.01-0.75)^{*}$ \\
\hline \multirow{2}{*}{$\begin{array}{l}\text { Households domestic waste } \\
\text { disposal place }\end{array}$} & Household waste pit & $45(35.7)$ & $60(23.8)$ & 1 & 1 \\
\cline { 2 - 6 } & Open area & $27(21.4)$ & $30(11.9)$ & $1.20(0.63-2.29)$ & $1.05(0.29-3.83)$ \\
\cline { 2 - 6 } & Burned & $54(42.9)$ & $162(64.3)$ & $0.44(0.27-0.73)^{*}$ & $0.79(0.22-2.87)$ \\
\hline \multirow{2}{*}{$\begin{array}{l}\text { Hand washing at the critical } \\
\text { time }\end{array}$} & Yes, Always & $102(81.0)$ & $229(90.9)$ & 1 & 1 \\
\cline { 2 - 6 } & Some times & $24(19.0)$ & $23(9.1)$ & $2.34(1.26-4.34)^{*}$ & $2.52(1.10-5.75)^{*}$ \\
\hline
\end{tabular}

*Significant at $\mathrm{p}<0.05$ 